\title{
ESTUDO EXPERIMENTAL DE SISTEMA DE ANCORAGEM POR CORDÃO DE FIBRAS DE CARBONO EM VIGAS REFORÇADAS AO CISALHAMENTO COM PRFC
}

\author{
Anchoring system experimental study of carbon fiber cord \\ reinforced shear beams with CFRP
}

\author{
Adriano Vieira RISSON ${ }^{1}$, Nara Villanova MENON ${ }^{2}$
}

Recebido em 22 de fevereiro de 2019; aceito em 28 de julho de 2019; disponível on-line em 11 de maio de 2020.

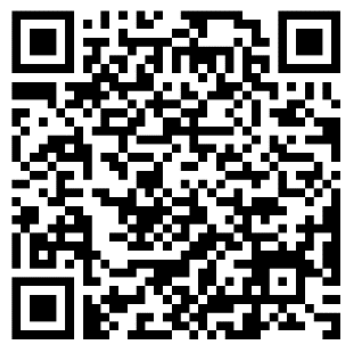

PALAVRAS CHAVE:

Concreto armado;

Fibras de carbono;

Reforço;

Ancoragem;

Vigas.

\section{KEYWORDS:}

Reinforced concrete; Carbon fibers;

Reinforcement;

Anchorage;

Beams.

* Contato com o autor:
RESUMO: O presente trabalho tem como objetivo avaliar o comportamento estrutural de vigas de concreto armado, reforçadas à flexão com tecido de fibras de carbono, utilizando mecanismo de ancoragem composto pela inserção de cordão de fibras de carbono no concreto. Foram utilizadas cinco vigas com o objetivo de avaliar o mecanismo aplicado em reforços de cisalhamento. Todas as vigas foram ensaiadas à aplicação de carregamentos transversais e instrumentadas para avaliar a carga de ruptura, deslocamento vertical, deformação específica no aço, concreto e reforço e o modo de ruptura. Através dos resultados, verificou-se que o mecanismo de ancoragem estudado atuou impedindo que o elemento estrutural chegasse a ruína prematuramente por descolamento ou desprendimento do reforço. Foram constatados ganhos principalmente na ductilidade das vigas e no aumento de sua capacidade resistente, que chegou a apresentar acréscimos superiores a $300 \%$ das vigas sem reforço. Através deste resultado, concluiu-se que o sistema de ancoragem por inserção de cordão de fibras de carbono se mostrou eficiente para ambos os tipos de reforço.

ABSTRACT: This study aims to evaluate the structural behavior of reinforced concrete beams, reinforced with carbon fiber fabric, using an anchoring mechanism composed of carbon fiber strand inserted in concrete. Five beams were used in order to evaluate the mechanism applied in shear reinforcements. All beams were applied to the transverse loadings and instrumented to measure the breaking load, vertical displacement, deformation specifically in steel, concrete and reinforcement and failure mode. The results concluded that the studied anchoring mechanism acts to prevent the structural element from premature destruction through detachment or loosening of the reinforcement. The main improvements were made in the ductility of the beams and increase in their load capacity, which made an increase of more than 300\% over unreinforced beams. Through this result, it was concluded that the mooring system by insertion of carbon fiber strand was efficient for both types of reinforcement.

${ }^{1}$ e-mail: adrianorisson@gmail.com (A. V. Risson)

Engenheiro Civil, Mestre em Engenharia Civil, Professor, Centro Universitário Dinâmica das Cataratas - UDC.

2e-mail: nvmenon@uem.br ( N. V. Menon)

Engenheira Civil, Doutora em Engenharia Civil, Professora, Universidade Estadual de Maringá - UEM. 


\section{INTRODUÇÃO}

A aplicação de compósitos de fibra de carbono no concreto armado tem sido difundida no mundo. A necessidade de recuperar estas estruturas, cada vez mais frequente, aliada a facilidade de execução, leveza, rapidez e trabalhabilidade do material, além da resistência à corrosão, podem ser considerados fatores importantes na difusão da utilização dos compósitos de fibra de carbono em substituição a outros reforços, como por exemplo, as chapas de aço.

O surgimento destas novas técnicas de reforço levou a uma crescente utilização em estruturas, no entanto, o fato da aplicação do compósito ser feita através de colagem gera uma necessidade de se estudar melhor o comportamento conjunto dos materiais, de modo a aumentar a confiança e segurança do reforço. Muitas publicações, tais como Borba (2015), Breña e McGuirk (2013) e Grelle e Sneed (2013) têm dado atenção especial à zona de ligação dos materiais concreto, adesivo e PRFC (Polímeros Reforçados com Fibras de Carbono), com o objetivo aprimorar o conhecimento do comportamento geral desta região, criando critérios para prevenir e eliminar as rupturas prematuras (MENON e PADARATZ, 2008).

$A$ aderência entre a manta de fibras de carbono e o substrato de concreto é um dos fatores mais estudados em pesquisas com esse sistema de reforço. Existe a possibilidade da ocorrência de ruptura prematura do elemento estrutural, caracterizada pela ocorrência nas extremidades do reforço, onde ocorre tensões elevadas normais e tangenciais, provocando 0 descolamento do compósito ao concreto (MENDES e COSTA, 2010).

A delaminação do reforço ou o descolamento do compósito, modos de ruptura de elementos reforçados, podem ocorrer se a força solicitante no PRF for maior que o substrato de concreto pode resistir (ACl 440.2R, 2008).

A distribuição da tensão de cisalhamento entre o substrato de concreto e o compósito de PRF pode variar de acordo com a intensidade da força de tração no reforço. Para cargas menores a concentração de tensões está localizada mais distante da extremidade de ligação entre o concreto e o reforço, enquanto que ao ponto que se eleva o carregamento, esse pico de tensões se aproxima do extremo do compósito (FIB-BULLETIN 14, 2004).

Desta forma, os estudos realizados se justificam pela necessidade de se conhecer melhor o comportamento da interface de ligação de elementos reforçados, bem como buscar novas alternativas para melhorar tais condições.

\section{OBJETIVOS}

O presente trabalho tem como objetivo analisar experimentalmente a eficiência da aplicação de sistema de ancoragem para reforço de vigas com fibra de carbono, submetidas ao cisalhamento, através da utilização de inserção de cordão de fibra de carbono no elemento de concreto.

\section{REVISÃO BIBLIOGRÁFICA}

Para Menon (2008), o comportamento do compósito de PRFC é linear até a sua ruptura, o que pode ser considerado um problema quanto à ductilidade da estrutura de concreto, principalmente levando em consideração ações sísmicas.

Entre os tipos de falha na aderência do compósito com o concreto estão o descolamento e a delaminação/desprendimento. A delaminação ou o descolamento do compósito PRF pode ocorrer se a força atuante no reforço não puder ser resistida pelo substrato de concreto. Esse comportamento é considerado como um desligamento, independentemente da região onde a falha acontece ( $\mathrm{ACl} 440-2 \mathrm{R}, 2008)$.

Para Fib-Bulletin 14 (2004), a definição de descolamento pode ser descrita como uma falha local na zona de aderência entre o concreto e o reforço.

De maneira geral, o descolamento do PRFC surge mesmo com u baixo nível de aumento de capacidade de carga do elemento submetido à flexão. Isso pode acontecer devido a problemas na fase de aplicação do reforço, como ancoragem 
inadequada e propriedades insuficientes das resinas (FERRARI, 2002).

A delaminação do reforço pode ser causada pelas tensões normais desenvolvidas nas extremidades do PRF, colado externamente. Nesse tipo de falha, a armadura de aço atua como um interruptor de ligação do concreto, fazendo com que o cobrimento da viga se afaste do restante do elemento estrutural ( $\mathrm{ACl} 440-2 \mathrm{R}, 2008$ ).

Chen e Teng (2001) afirmam que o principal modo de falha de reforços em Polímeros Reforçados com Fibras (PRF) acontece pelo efeito de tensões de cisalhamento no concreto, ocorrendo geralmente a poucos milímetros da superfície de colagem do compósito.

Para Grelle e Sneed (2013), apesar de a ligação do PRF ser o papel crítico do sistema de reforço em uma viga de concreto reforçada, há uma falta de conhecimento aprofundado sobre o comportamento dos sistemas de ancoragem do reforço.

Para CNR-DT 200 (2004), quando utilizados sistemas de ancoragem especiais, pode-se desconsiderar a aplicação de coeficientes de segurança específicos para o caso de delaminação, desde que se tenha certificação do dispositivo de ancoragem baseada em estudos experimentais. Tais estudos devem apresentar os materiais utilizados, o sistema específico, a sequência de aplicação fornecida pelo fabricante, os tempos de execução e condições ambientais.

Entretanto, conforme a $\mathrm{ACl} 440-2 \mathrm{R}$ (2008), o desempenho estrutural de qualquer sistema de ancoragem de reforço em PRF deve ser fundamentado por testes.

\section{METODOLOGIA}

Foram analisadas 5 vigas de concreto armado com seção transversal de 12 centímetros de base e 25 centímetros de altura, moldadas exatamente com as mesmas características e condições de fabricação e cura. Estas foram ensaiadas à flexão para analisar seu comportamento perante as solicitações, verificando a contribuição dos mecanismos de ancoragem.

A análise experimental consistiu em ensaios à flexão por 3 pontos. As vigas tiveram suas armaduras longitudinal e transversal dimensionadas igualmente. Essas vigas foram divididas conforme composição de reforço e incremento de ancoragem das fibras.

As armaduras foram dimensionadas de forma que a ruptura aconteça por escoamento dos estribos e não por flexão. Para isso, a armadura longitudinal foi superdimensionada, utilizando-se o processo momento $x$ curvatura.

A armadura transversal foi calculada pelos critérios da norma brasileira NBR 6118 (ABNT, 2014), sendo, neste caso, subdimensionadas. Para isso, as vigas foram fabricadas com armadura longitudinal composta por quatro barras de aço CA50, com $16,0 \mathrm{~mm}$ de diâmetro, sendo duas superiores e duas inferiores. $A$ armadura transversal foi formada por estribos de aço CA-60, com 4,2 mm de diâmetro e espaçados a cada $18 \mathrm{~cm}$.

No Quadro 1 são apresentadas as características de cada viga analisada e sua nomenclatura.

\begin{tabular}{|c|c|}
\hline VCR & Viga de referência, sem reforço \\
\hline VCO-90 & $\begin{array}{l}\text { Viga com reforço em manta de fibra de carbono em tiras, orientadas à } 90^{\circ} \text { com relação ao } \\
\text { seu eixo }\end{array}$ \\
\hline VC1 & $\begin{array}{l}\text { Viga com reforço em manta de fibra de carbono em tiras, orientadas à } 90^{\circ} \text { com relação ao } \\
\text { seu eixo, com o sistema de ancoragem }\end{array}$ \\
\hline VC2 & $\begin{array}{l}\text { Viga com reforço em manta de fibra de carbono em tiras, orientadas à } 90 \text { ㅇ com relação ao } \\
\text { seu eixo, com o sistema de ancoragem }\end{array}$ \\
\hline VC3 & $\begin{array}{l}\text { Viga com reforço em manta de fibra de carbono em tiras, orientadas à } 90 \text { 으 com relação ao } \\
\text { seu eixo, com o sistema de ancoragem }\end{array}$ \\
\hline
\end{tabular}


Foi executada uma viga de referência (VCR), construída somente em concreto armado, sem a utilização de algum tipo de reforço. Esta serviu como parâmetro de referência para comparações com valores de rigidez das demais vigas, variando de acordo com a utilização dos reforços propostos.

A viga VCO-90 foi construída a partir da configuração original, com o incremento da utilização de reforço ao cisalhamento em manta de fibra de carbono, por meio da colagem do tecido nas faces laterais dos elementos de concreto armado, por tiras orientadas a 900 em relação ao eixo das vigas. Estes modelos também serviram para, além de comparar o aumento da rigidez provocado pela aplicação do reforço, também possibilitar a determinação de valores de referência para um comparativo com as vigas que serão construídas com o sistema de ancoragem da manta. Por meio destes ensaios também foi possível analisar o comportamento das vigas reforçadas, bem como o modo de ruptura prematuro causado pelo descolamento ou desprendimento da manta.

As vigas VC1, VC2 e VC3 foram executadas idênticas ao modelo da viga VC0-90, porém com o incremento de ancoragem do reforço por meio do cordão de fibras de carbono, posicionados nas extremidades das tiras.

Para estes modelos, objetivou-se analisar o aumento da rigidez das vigas que utilizam o sistema de ancoragem, com relação às vigas sem o sistema. Assim, foi possível analisar o modo de ruptura das mesmas.

Por os diâmetros das barras longitudinais serem elevados, foram utilizadas chapas metálicas como dispositivos de ancoragem. Estes chapas dispunham de quatro furos, onde as barras longitudinais foram soldadas.

O posicionamento do mecanismo de ancoragem seguiu a mesma concepção das vigas reforçadas ao cisalhamento, sendo aplicados nas extremidades do tecido.

Para as vigas VC0-90, VC1, VC2 e VC3, os tecidos foram aplicados com envolvimento em " $\mathrm{U}$ ".

As faixas tiveram largura de $50 \mathrm{~mm}$ para todos os casos. Os detalhamentos do reforço ao cisalhamento em fibras de carbono são mostrados na Figura 1.

Os cobrimentos utilizados para a armadura foram de 1,5 cm, conforme prescrições da NBR 6118 (ABNT, 1978), objetivando a aplicabilidade em estruturas mais antigas, as quais mais necessitam de reforço.

O mecanismo de ancoragem estudado visa evitar ou retardar o desprendimento do reforço, através do aumento da rigidez do PRFC em suas extremidades. $O$ tecido foi aplicado em apenas uma camada na face tracionada da viga, no sentido longitudinal ao seu eixo, e sem envolvimento lateral.

O posicionamento do sistema de ancoragem foi definido baseado em alguns estudos que apresentam a região de maior tensão entre o reforço e o concreto. Em função da falta de outros estudos que apresentem o comportamento do mecanismo quando solicitado, optou-se por utilizar essa configuração, podendo ser estendida a pesquisa com outras variáveis, em trabalhos futuros.

O início da aplicação do sistema de ancoragem se deu com a marcação do posicionamento que iriam ser executados.

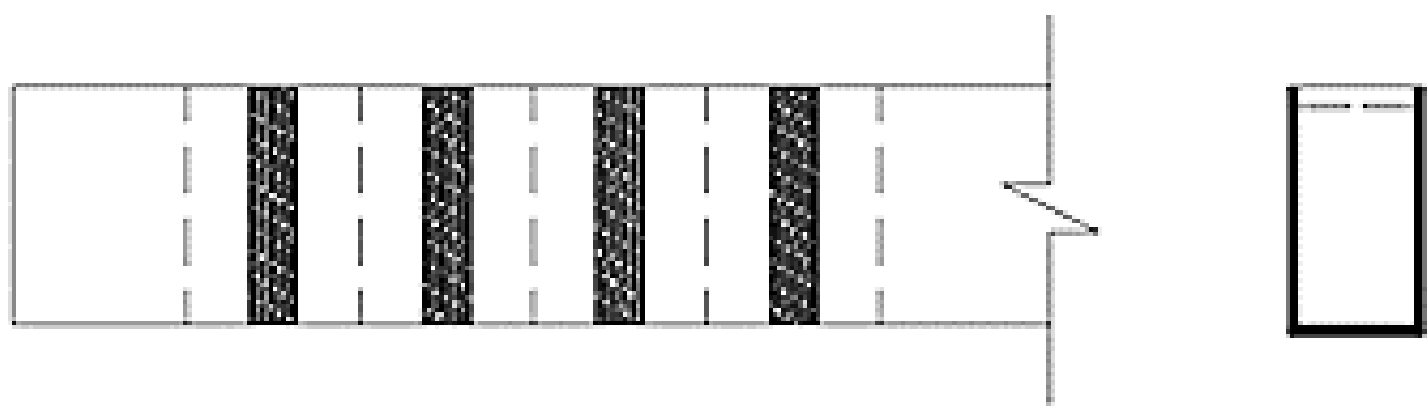

FIGURA 1: Detalhamento dos sistemas de reforço ao cisalhamento FONTE: Autores (2018) 
Após a determinação do local onde seriam executadas as ancoragens, fez-se a furação do concreto onde funcionaria o sistema de ancoragem. Os furos foram feitos com o auxílio de furadeira de impacto equipada com broca de diâmetro de $18 \mathrm{~mm}$ e com profundidade de $100 \mathrm{~mm}$. O processo de preparação para aplicação do mecanismo é mostrado na Figura 2.

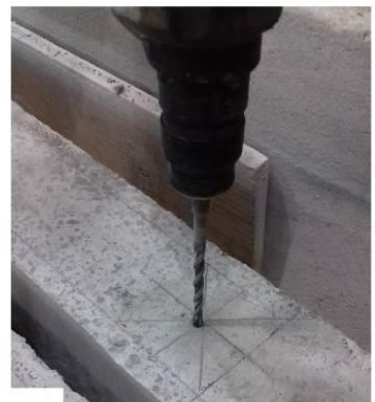

(a)
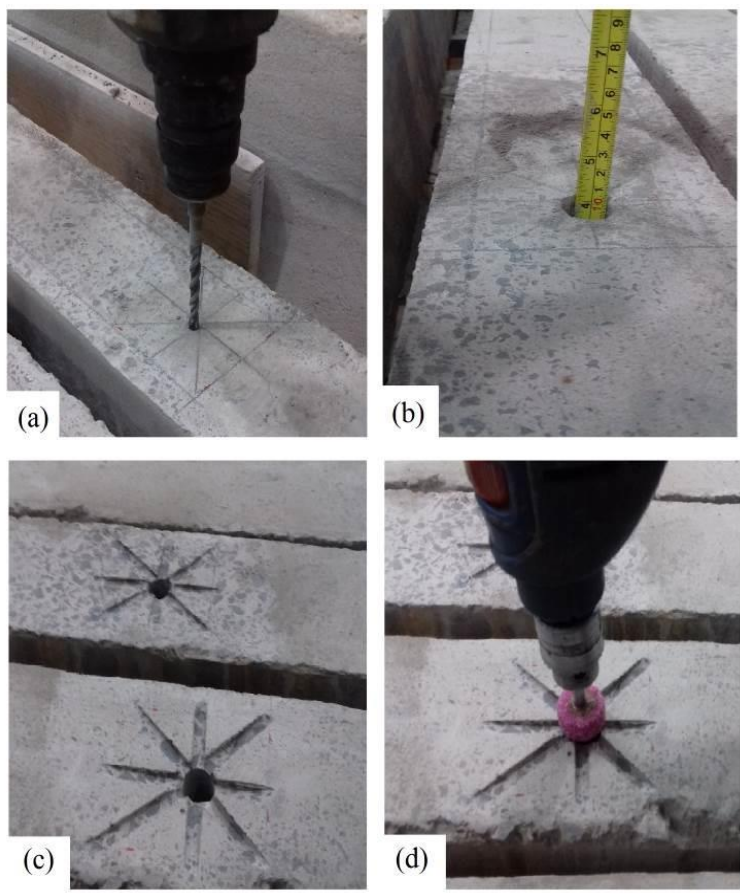

FIGURA 2: Preparação para aplicação da ancoragem: [a] furação; [b] conferência da profundidade; [c] execução das fendas, e; [d] arredondamento dos cantos FONTE: Autores (2018)

A aplicação do cordão de fibras de carbono como ancoragem foi realizada seguindo as seguintes etapas. Primeiramente o cordão é cortado ligeiramente maior que a profundidade do furo. $\mathrm{O}$ cordão é impregnado com a resina, amarrado na extremidade com abraçadeira plástica para facilitar sua inserção.

Em seguida os furos foram preenchidos com o adesivo de injeção até próximo à superfície. O cordão, com comprimento maior que a profundidade do furo, tem seu excesso dividido nas oito fendas feitas no concreto e fixada com o adesivo de impregnação do reforço. $O$ sistema de ancoragem aplicado é mostrado na Figura 3.

A aplicação do carregamento se fez com apenas uma carga concentrada, posicionada próxima de um dos extremos da viga. Dessa forma, pôde-se conduzir a ruptura da viga ao lado com maior força cortante. Também foi possível instrumentar a viga somente no lado mais carregado.

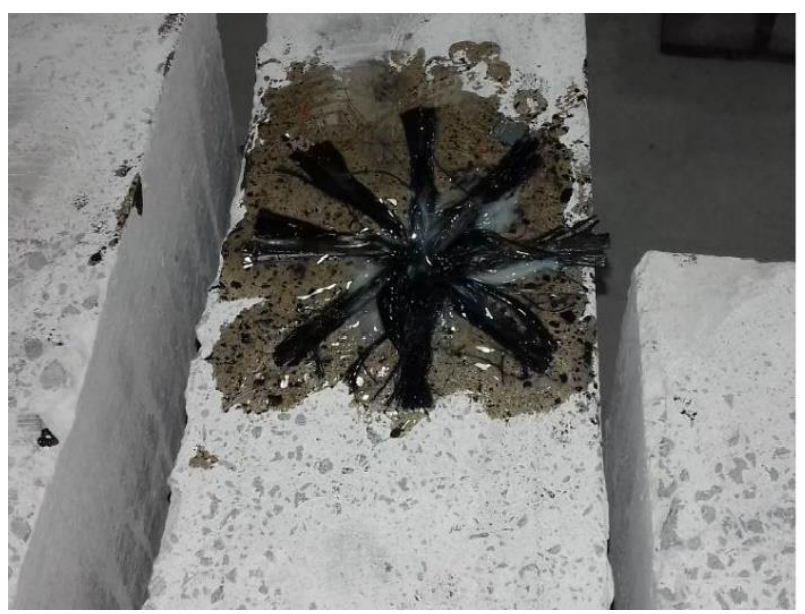

FIGURA 3: Sistema de ancoragem aplicado FONTE: Autores (2016)

Os resultados obtidos dos ensaios foram tratados de forma a obter o comportamento dos componentes estruturais que contribuem para a resistência ao cisalhamento da viga. Para isso, foram analisadas as deformações na armadura transversal e no reforço, carga e modo de ruptura.

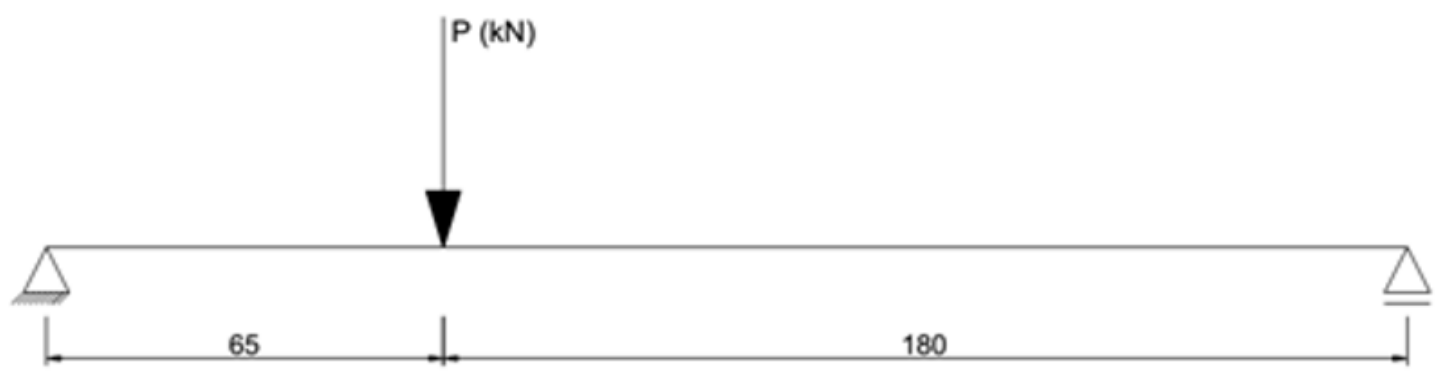

FIGURA 4: Esquema de ensaio FONTE: Autores (2018) 


\section{RESULTADOS E DISCUSSÕES}

Neste capítulo são apresentados os resultados das cargas de rupturas, deslocamentos verticais e deformações nos materiais de cada viga.

\subsection{CARGA E RUPTURA}

Para esta análise foram comparadas as cargas e o modo de ruína das vigas VCR, VCO-90, VC1, VC2 e VC3. Na Tabela 1 são apresentados os resultados de cada viga, relacionado com o modo de ruína.

Nota-se que a viga reforçada com PRFC sem o mecanismo de ancoragem obteve um aumento de resistência relativamente pequeno em relação à viga de referência VCR. Isso se deve à ocorrência do descolamento prematuro do compósito.

Beber (2003) explica que o descolamento do reforço está associado, entre outros fatores, a uma fissura diagonal de tração. Este descolamento acontece próximo à essa fissura. Após iniciado o descolamento do reforço, a ruína da viga acontece rapidamente, sendo que somente a aderência entre o compósito em PRFC e o substrato de concreto pode controlar esse colapso.

Chen, Teng e Chen (2013) afirmam que as vigas reforçadas ao cisalhamento com tiras laterais ou envolvimento em " $U$ " costumam falham por descolamento do compósito. Esse descolamento acontece, geralmente, de forma frágil, com pequenas fissuras. Em alguns casos, os estribos da viga podem nem ter sido solicitados à tensão de escoamento do aço. Esses fatos podem reduzir significativamente os benefícios do reforço em PRFC.
Verifica-se nesse caso que a aderência entre o compósito e o substrato de concreto da viga VC0-90 não foi eficiente ao ponto de retardar significativamente o colapso da viga. As análises das deformações dos materiais componentes da viga devem complementar as conclusões.

Analisando as vigas reforçadas e que dispunham do mecanismo de ancoragem composto pela inserção do cordão de fibras de carbono, verificou-se um incremento de resistência significativo. Exceto a viga VC1, que apresentou acréscimo de carga de $129,28 \%$, as demais vigas com esse mecanismo obtiveram carregamento de ruptura em média $279,50 \%$ maior que a viga de referência.

Beber (2003), em sua pesquisa experimental, analisou vigas reforçadas ao cisalhamento com tiras de PRFC com envolvimento em " $U$ ". Nesta pesquisa, o autor observou o colapso das vigas do referido grupo por descolamento do reforço e seu incremento de ancoragem, para as três vigas estudadas, foi de 72,9\%, 119,3\% e 63,3\%.

Em outro grupo, Beber (2003) analisou o mesmo sistema de reforço, porém com envolvimento completo das tiras, evitando o descolamento do compósito. Para estas vigas o colapso aconteceu por ruptura do reforço, e tiveram como incremento de resistência 104,4\%, 123,6\% e $146,2 \%$ em relação à viga de referência.

Menon (2008) analisou em sua pesquisa, vigas reforçadas com tiras de fibras de carbono orientadas à 90 ㅇ em relação ao eixo da viga, aplicadas com envolvimento completo. Para estas vigas, foi observado colapso por flexão, sem descolamento ou ruptura do reforço. Nestes casos o acréscimo de resistência foi de 51\% em média.

TABELA 1: Cargas de ruína das vigas reforçadas ao cisalhamento.

\begin{tabular}{cccc} 
Viga & Carga (kN) & Incremento (\%) & Modo de ruína \\
\hline VCR & 85,31 & - & Cisalhamento \\
VC0-90 & 102,51 & 20,16 & Descolamento do reforço \\
VC1 & 195,60 & 129,28 & Arrancamento do mecanismo de ancoragem \\
VC2 & 312,91 & 266,79 & Cisalhamento no trecho não reforçado \\
VC3 & 334,59 & 292,20 & Cisalhamento do trecho não reforçado \\
\hline
\end{tabular}

FONTE: Autores (2016) 


\subsection{CONTRIBUIÇÃO DO REFORÇO}

Considerando os conceitos utilizados pelos códigos normativos de dimensionamento de elementos de concreto armado, reforçados com PRFC, com relação ao esforço cortante, tem-se:

$$
V_{u}=V_{c}+V_{s w}+V_{f}
$$

Em que:

$\mathrm{Vu}$ : Força cortante última $(\mathrm{kN})$;

Vc: Contribuição do concreto (kN);

Vsw: Contribuição da armadura transversal (kN), e;

Vf: Contribuição do PRFC (Kn).

Na Figura 5 é apresentado o valor da força cortante última de cada viga, bem como as parcelas de contribuição do concreto, aço e reforço. $O$ valor da contribuição do concreto e do aço foram obtidos através do resultado da viga de referência.

Nota-se, através dos resultados, que a ancoragem do reforço é um fator preponderante na eficiência do sistema, e que pode levar a resultados satisfatórios.

\subsection{DESLOCAMENTOS VERTICAIS}

O deslocamento vertical observado na viga depende de alguns fatores como carga aplicada, vão, tipos de vinculação, características dos materiais e geométrica da peça.

A aplicação de reforço em PRFC em vigas de concreto armado são praticamente desprezíveis para o aumento de sua seção transversal. Entretanto, pelas propriedades da fibra de carbono, o momento de inércia de sua seção tem aumento significativo, influenciando diretamente na rigidez do elemento estrutural.

Na Figura 6 é apresentado o comparativo dos deslocamentos verticais no meio do vão de todas as vigas estudadas.

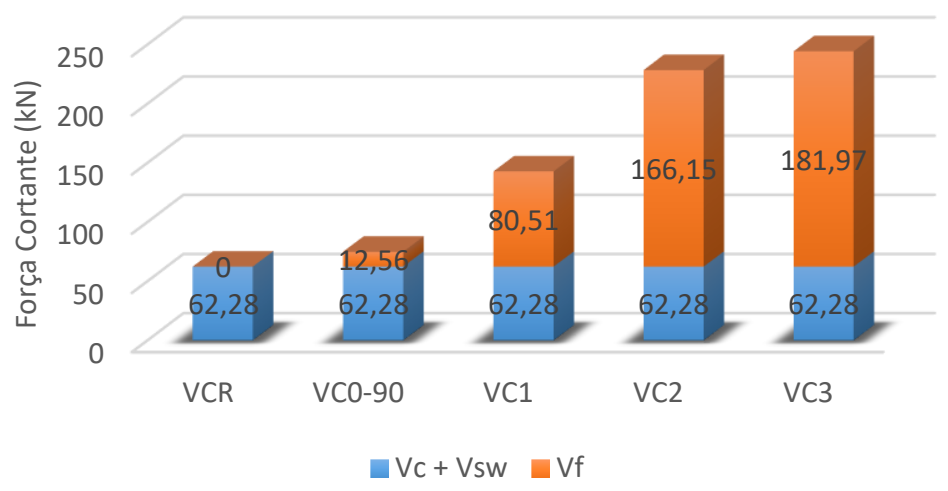

FIGURA 5: Contribuição do concreto, aço e PRFC das vigas FONTE: Autores (2018)

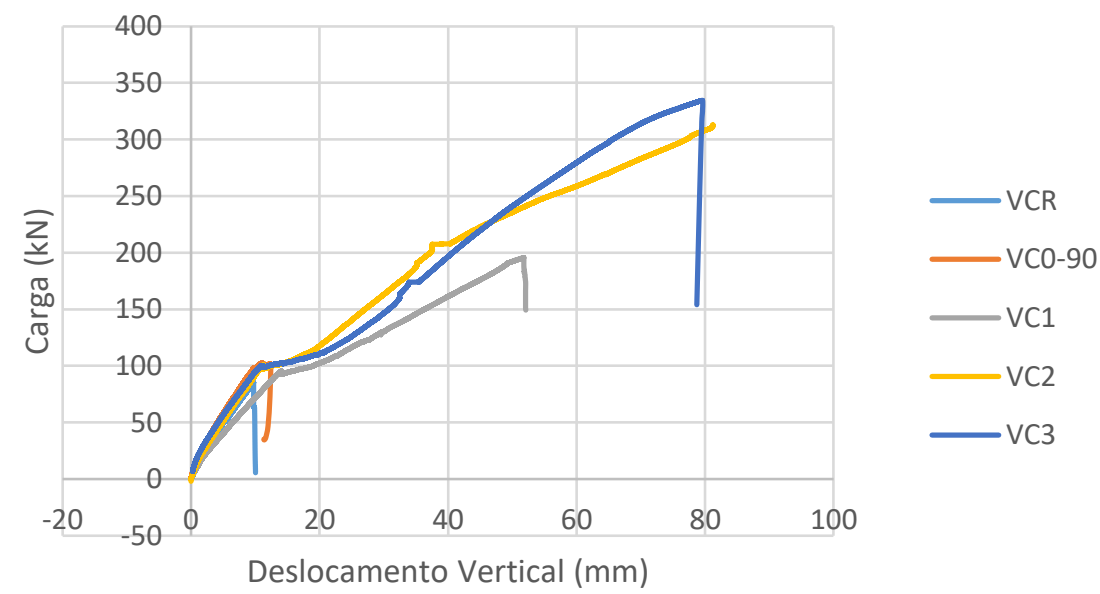

FIGURA 6: Deslocamento vertical das vigas FONTE: Autores (2018) 
É possível avaliar que o reforço utilizado resulte no aumento significativo da ductilidade das vigas. Com a utilização do mecanismo de ancoragem, e consequentemente o incremento de resistência, pôde-se observar deslocamentos consideravelmente maiores no ponto de colapso, comparando com a viga de referência.

Entretanto, verificou-se que as vigas tiveram comportamento semelhante quanto à sua rigidez, até aproximadamente $100 \mathrm{kN}$ de carga. Nesse sentido, semelhante à conclusão obtida por Beber (2003), é impossível qualquer consideração quanto à uma possível elevação da rigidez das vigas ocasionadas pela aplicação do reforço.

\subsection{DEFORMAÇÃO ESPECÍFICA NA ARMADURA}

Com a utilização da instrumentação, pôdese observar o comportamento das deformações da armadura a partir da atuação do reforço. A deformação nos estribos do grupo de vigas reforçadas ao cisalhamento é mostrada na Figura 7.

Verifica-se, através dos resultados, que a contribuição dos estribos nas primeiras cargas é praticamente nula. Após o surgimento das primeiras fissuras de cisalhamento, que ocorreram com cargas entre $40 \mathrm{kN}$ e $50 \mathrm{kN}$, o aço iniciou sua deformação até o escoamento ou ruptura.

\subsection{DEFORMAÇÃO ESPECÍIFCA NO REFORÇO}

Analisando os resultados já apresentados, pode-se comprovar que a utilização de reforços em PRFC em vigas de carbono tem papel fundamental no aumento da rigidez e da resistência final das vigas.

Os valores de deformação específica do reforço obtidos nesta pesquisa visam complementar os efeitos ocorridos à aplicação das cargas. A Figura 8 apresenta o comparativo das deformações específicas ocorridas no compósito de PRFC.

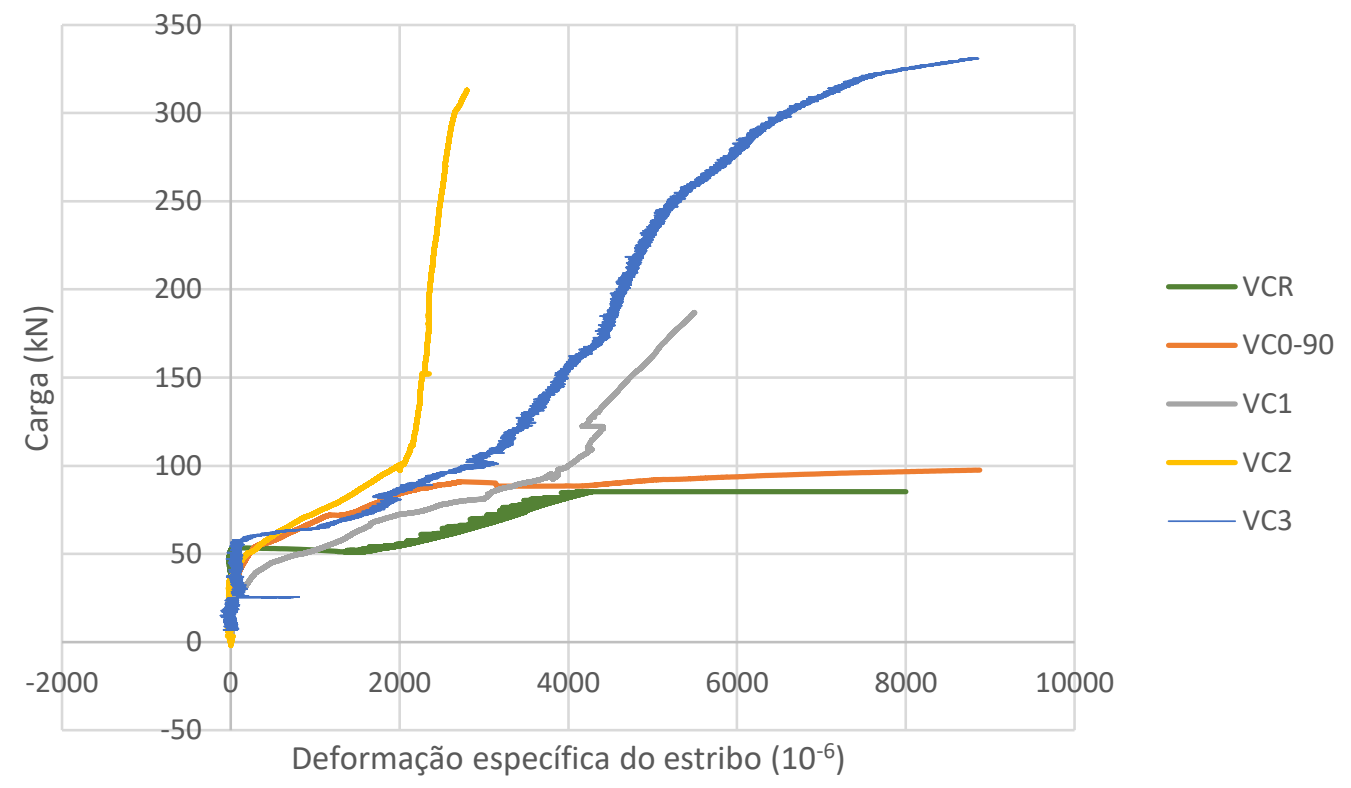

FIGURA 7: Defornação específica nos estribos FONTE: Autores (2018) 


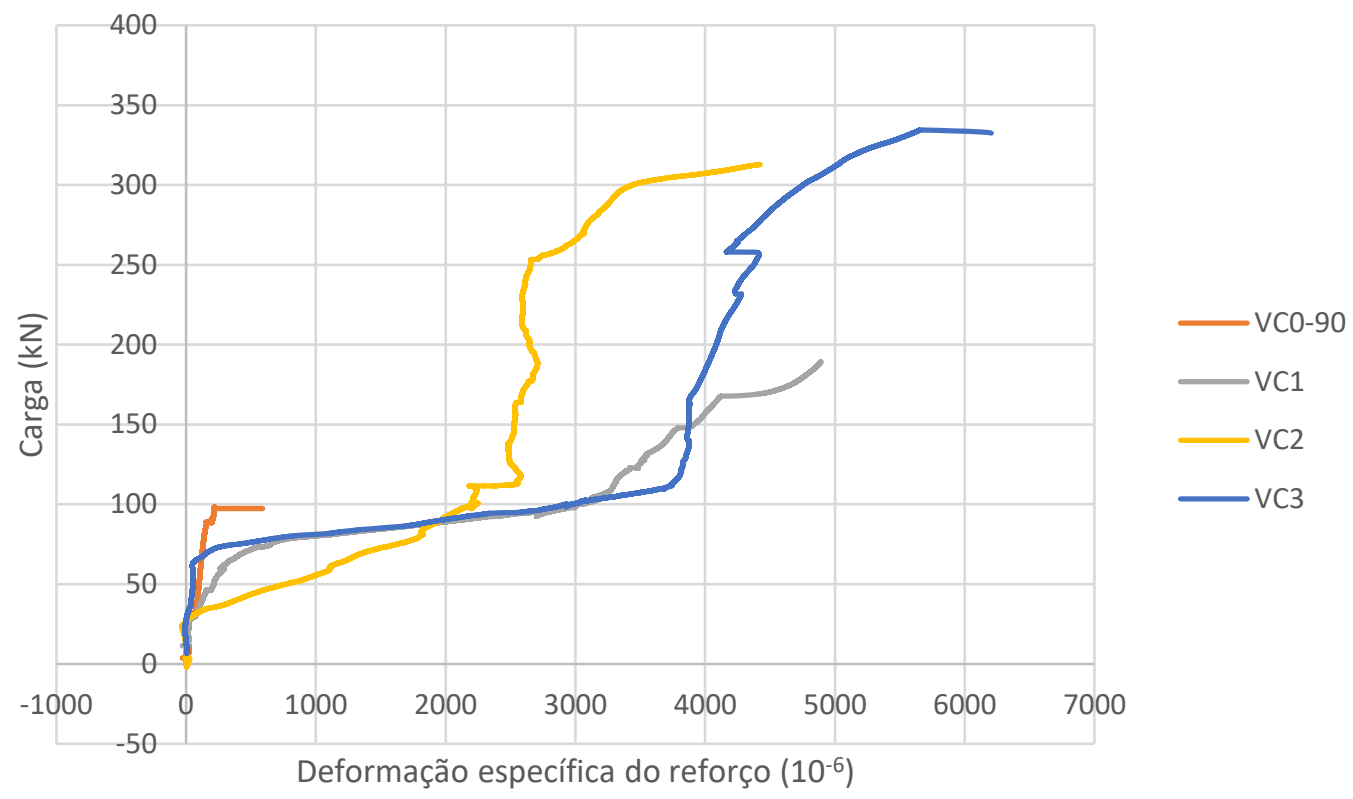

FIGURA 8: Defornação específica no reforço FONTE: Autores (2018)

Verificou-se que as deformações dos reforços se iniciaram logo nas primeiras cargas, a partir de $30 \mathrm{kN}$, porém foram mais expressivos após o carregamento referente ao surgimento da primeira fissura de cisalhamento.

É possível observar que logo após o início da contribuição do reforço na viga VCO-90, houve o descolamento do compósito, impossibilitando o aproveitamento de sua capacidade resistente.

Para as vigas VC1, VC2 e VC3, constatou-se dois estágios de deformação. $\mathrm{O}$ primeiro aconteceu após a carga do surgimento da primeira fissura diagonal, e se estendeu até uma possível carga de descolamento do compósito, com aproximadamente $100 \mathrm{kN}$ (baseada no descolamento ocorrido na viga VCO-90). Já no segundo estágio, verificou-se uma atuação maior do reforço, caracterizado pela minoração do crescimento da deformação, combinado com o acréscimo de carga repentino.

\section{CONCLUSÕES}

Conforme resultados de pesquisas já publicadas em outras bibliografias, constatou-se um excelente desempenho das vigas reforçadas com fibra de carbono quanto ao incremento de capacidade de carga e ductilidade das vigas.

A viga reforçada sem o mecanismo de ancoragem proposto apresentou modo de ruptura frágil, caracterizado pelo desprendimento do tecido em fibra de carbono do substrato de concreto. Porém, com a inserção do sistema de ancoragem composto por cordão de fibra de carbono, as vigas estudadas apresentaram colapso caracterizado pela ruptura do reforço.

A leitura das deformações específicas mostrou que o reforço nas vigas acaba retardando o início do escoamento do aço e, também, diminui a deformação no concreto.

Observou-se incremento de capacidade resistente das vigas compostas pelo sistema de ancoragem de até $292 \%$. O aumento de ductilidade das vigas também foi verificado.

As vigas que utilizaram o mecanismo de ancoragem apresentaram panorama de fissuração mais evidente, com grande densidade de fissuras.

Por fim, verifica-se que o sistema estudado pode possibilitar o aproveitamento da capacidade máxima de tração do reforço, sem o descolamento ou desprendimento do compósito. Por meio das análises, verificou-se uma contribuição considerável em relação ao aumento da capacidade de carga e da ductilidade dos elementos estruturais. 


\section{AGRADECIMENTOS}

Ao Centro Universitário Dinâmica das Cataratas (UDC) pela disponibilização dos equipamentos e laboratórios, e à Sika do Brasil pelo fornecimento dos materiais de reforços.

\section{REFERÊNCIAS BIBLIOGRÁFICAS}

AMERICAN CONCRETE INSTITUTE. ACI 440.2R: Guide for the design and construction of externally bonded FRP systems for strengthening concrete st. Farmington Hills, 2008.

ASSOCIAÇÃO BRASILEIRA DE NORMAS TÉCNICAS. ABNT NBR 6118: Projeto de estruturas de concreto procedimento. Rio de Janeiro, 2014.

BEBER, Andrei José. Comportamento estrutural de vigas de concreto armado reforçadas com compósitos de fibra de carbono. 2003. 289 f. Tese (Doutorado) - Curso de Programa de Pós Graduação em Engenharia Civil, Universidade Federal do Rio Grande do Sul, Porto Alegre, 2003.

BORBA, Maria Isabel Santos. Comportamento da ligação CFRP/betão em estruturas de betão armado. 2015. 141 f. Dissertação (Mestrado) - Universidade Nova de Lisboa, Lisboa, 2015.

BREÑA, Sergio F.; MCGUIRK, Geoffrey N.. Advances on the Behavior Characterization of FRP-Anchored Carbon Fiber-Reinforced Polymer (CFRP) She. International Journal Of Concrete Structures And Materials. [s.I.], p. 316. mar. 2013.

CHEN, J. F.; TENG, J. G.. Anchorage strenght models for FRP and steel plates bonded to concrete. Journal of Structural Engineering. [S.I.], p. 784-791, 2001.

CHEN, G. M.; TENG, J. G.; CHEN, J. F.. Shear Strength Model for FRP-Strengthened RC Beams with Adverse FRPSteel Interaction. Journal of Composites For Construction. [S.I.], p. 50-66. fev. 2013.

CONSIGLIO NAZIONALE DELLE RICERCHE. CNR-DT 200: Istruzioni per la progettazione, l'esecuzione ed il controllo di interventi di consolidamento static. Roma, 2004.

FÉDÉRATION INTERNATIONALE DU BÉTON. BULLETIN 14: Design and use of externally bonded fibre reinforced polymer reinforcement (FRP EBR) for reinforced concrete structures. Patras, 2001.

FERRARI, Vladimir José. Reforço à flexão em vigas de concreto armado com manta de fibra de carbono: mecanismos de incremento de ancoragem. 2002. $213 \mathrm{f}$. Dissertação (Mestrado) - Universidade Federal de Santa Catarina, Florianópolis, 2002.

GRELLE, Stephen V.; SNEED, Lesley H.. Review of Anchorage Systems for Externally Bonded FRP Laminates. International Journal of Concrete Structures And Materials. [s.I.], p. 17-33. mar. 2013.

MENDES, Rui Veloso; COSTA, António da Silva. Sistemas de Ancoragem para Laminados CFRP em elementos de Betão Armado. Encontro Nacional Betão Estrutural, Lisboa, out. 2010.

MENON, Nara Villanova. Estudo experimental de sistemas de reforço ao cisalhamento em vigas de concreto armado utilizando-se polímero reforçado com fibras de carbono (PRFC). 2008. $332 \mathrm{f}$. Tese (Doutorado) - Universidade Federal de Santa Catarina, Florianópolis, 2008.

MENON, Nara Villanova; PADARATZ, Ivo José. Desempenho de duas técnicas de reforço ao cisalhamento em vigas de concreto armado através de inserção de laminados de CFRP. Revista Tecnológica, [S.I.], v. 17, p.19-28, 2008. 